\title{
Perinatal HIV transmission and the cost-effectiveness of screening at I 4 weeks gestation, at the onset of labour and the rapid testing of infants
}

\author{
Belinda Udeh¹, Chiedozie Udeh ${ }^{2}$ and Nicholas Graves*3
}

Address: ${ }^{1}$ Public Policy Center, University of Iowa, Iowa City, Iowa, USA, ${ }^{2}$ University of Iowa Hospitals and Clinics, University of Iowa, Iowa City, Iowa, USA and ${ }^{3}$ Institute of Health \& Biomedical Innovation, Queensland University of Technology, Brisbane, Queensland, Australia

Email: Belinda Udeh - belinda-udeh@uiowa.edu; Chiedozie Udeh - chiedozie-udeh@uiowa.edu; Nicholas Graves* - n.graves@qut.edu.au

* Corresponding author

Published: 31 December 2008

BMC Infectious Diseases 2008, 8:174 doi:10.1/86/147|-2334-8-174
Received: 3I May 2008

Accepted: 31 December 2008

This article is available from: http://www.biomedcentral.com/I47I-2334/8/174

(c) 2008 Udeh et al; licensee BioMed Central Ltd.

This is an Open Access article distributed under the terms of the Creative Commons Attribution License (http://creativecommons.org/licenses/by/2.0), which permits unrestricted use, distribution, and reproduction in any medium, provided the original work is properly cited.

\begin{abstract}
Background: Preventing HIV transmission is a worldwide public health issue. Vertical transmission of HIV from a mother can be prevented with diagnosis and treatment, but screening incurs cost. The U.S. Virgin Islands follows the mainland policy on antenatal screening for HIV even though HIV prevalence is higher and rates of antenatal care are lower. This leads to many cases of vertically transmitted HIV. A better policy is required for the U.S. Virgin Islands.
\end{abstract}

Methods: The objective of this research was to estimate the cost-effectiveness of relevant HIV screening strategies for the antenatal population in the U.S. Virgin Islands. An economic model was used to evaluate the incremental costs and incremental health benefits of nine different combinations of perinatal HIV screening strategies as compared to existing practice from a societal perspective. Three opportunities for screening were considered in isolation and in combination: by 14 weeks gestation, at the onset of labor, or of the infant after birth. The main outcome measure was the cost per life year gained (LYG).

Results: Results indicate that all strategies would produce benefits and save costs. Universal screening by 14 weeks gestation and screening the infant after birth is the recommended strategy, with cost savings of $\$ 1,122,787$ and health benefits of 310 LYG. Limitations include the limited research on the variations in screening acceptance of screening based on specimen sample, race and economic status. The benefits of screening after 14 weeks gestation but before the onset of labor were also not addressed.

Conclusion: This study highlights the benefits of offering screening at different opportunities and repeat screening and raises the question of generalizing these results to other countries with similar characteristics.

\section{Background}

Perinatal transmission causes most HIV infection among new born infants [1]. Transmission occurs during pregnancy, at the time of delivery or through breast milk [2].
The risk of perinatal HIV transmission can be reduced from $13-43 \%$ to less than 2\% [3-5] if an accurate diagnosis is made and appropriate treatment provided. Universal antenatal screening for HIV in pregnancy is now advo- 
cated in a number of countries $[6,7]$ and a number of costeffectiveness studies have been published [8-12]. These describe high income settings where HIV prevalence is low, prenatal care is widely available and adherence is good and typically screening is offered once during the $1^{\text {st }}$ trimester $[8,9,13]$. There is also literature that describes low income countries where the HIV prevalence is high but health resources are quite scarce making treatment options limited after diagnosis $[10,11]$. There is little research for settings where prevalence is relatively high and adherence to prenatal care is low, yet resources are available to make an accurate diagnosis and deliver effective therapy. In this case there is a clinical rationale for offering a diagnostic test to women who present in the first trimester and again at the onset of labour and for the rapid testing of infants. The process of repeat screening will overcome the problem of poor adherence to prenatal care and also captures women who may not have seroconverted at the time of the first test and women who contract the virus after the first screen. There is evidence that risks of perinatal transmission can be mitigated if a diagnosis is made at the onset of labor $[14,15]$ and if the infant is screened $[2,16]$, however, repeat screening regimens will incur costs and these must be balanced against health benefits.

In the U.S. Virgin Islands, less than $70 \%$ of women received antenatal care within the first trimester and of these women, less than $30 \%$ are screened for HIV $[17,18]$. The aim for this study is to develop a model of the incremental costs and incremental health benefits of nine different combinations of perinatal HIV screening strategies compared to existing practice. Three screening opportunities and all logical combinations are evaluated. These include screening by 14 weeks gestation during prenatal care, screening at the onset of labour and screening of the infant within 24 hours of birth. An alternative to the Enzyme Linked Immunoassay (EIA) screening tests is also considered, this is a rapid point of care test (Orasure ${ }^{\circledast}$ ). The setting is the U.S. Virgin Islands which is an upper income setting, although on the low end of the World Bank classification scale (GDP US $\$ 15,000$ per capita [19]). It has a population of around 110,000, over 1500 births per year [20], and has relatively high prevalence of antenatal HIV. It is a U.S. territory with many of its health policies adopted from the mainland U.S. even though its population characteristics and resource availability is considerably different. The results from this study can be generalized to other settings where prevalence is relatively high, adherence to prenatal care is poor yet resources are available for screening and treatment.

\section{Methods}

Overview

A cost-effectiveness decision-analytic model was built using TreeAge Pro $^{\circledast}$. A societal perspective was adopted to include the relevant health service costs, private costs and production losses. The expected incremental costs and health benefits, expressed as life years gained, of all logical alternate screening strategies were compared to existing practice at the decision node. See Figure 1 for a list of the strategies evaluated. The following uncertain events were built into the tree: HIV negative versus HIV positive woman; woman seeks prenatal care versus doesn't seek prenatal care; woman accepts screening versus declines screening; HIV test positive versus negative; pregnancy terminated versus not terminated; woman accepts ART therapy versus declines ART; HIV averted in infant versus HIV positive infant. All cost and benefit data was collected for a reference year of 2004 and were counted in \$US. Data values were verified by local experts where relevant. All future costs and benefits were discounted at a rate of 3\% in line with current recommendations [21]. Ethical permission for the study was granted by the Queensland University of Technology Research Ethics Committee.

\section{Incremental Costs}

Values for all relevant costs were included. The incremental cost of implementing the screening program included the costs of treating true HIV positive and false HIV positive mothers while pregnant, the treatment associated with early diagnosis in HIV positive mothers after delivery and HIV positive children, and the avoided treatment costs from preventing a case of HIV. The cost savings were deducted from all other positive costs to derive a net cost of the alternate screening strategy. It was assumed that all women would receive pre and post test counseling. An EIA test would be used for women who were screened by 14 weeks during antenatal care and rapid point of care test $\left(\right.$ Orasure $^{\circledast}$ ) for those women screened at the onset of labour or those infants screened within 24 hours birth. All positives were confirmed with a western blot. For false positives from rapid testing, treatment would be offered because a confirmation of HIV status would not be available before treatment would have to be commenced. For all infants born to HIV positive mothers, confirmation of their HIV status would be through the use of a HIV Polymerase Chain Reaction (PCR) test at time intervals in line with the U.S. Preventive Services Taskforce Guidelines [2]. All true positives and false positives identified at the onset of labor or by screening the infant after birth would begin appropriate medical therapy in accordance with current guidelines including prophylaxis for infants born to HIV positive mothers [7]. Medical treatment costs would also be included for all HIV positive women up until the time they would have been diagnosed by other means, with similar costs included for all infants who contract HIV despite screening and prophylaxis up until the time they would have otherwise been diagnosed. The lifetime costs of treating a case of HIV were determined from the rate of disease progression of the infant. For each case of HIV avoided, the lifetime costs of treatment and 


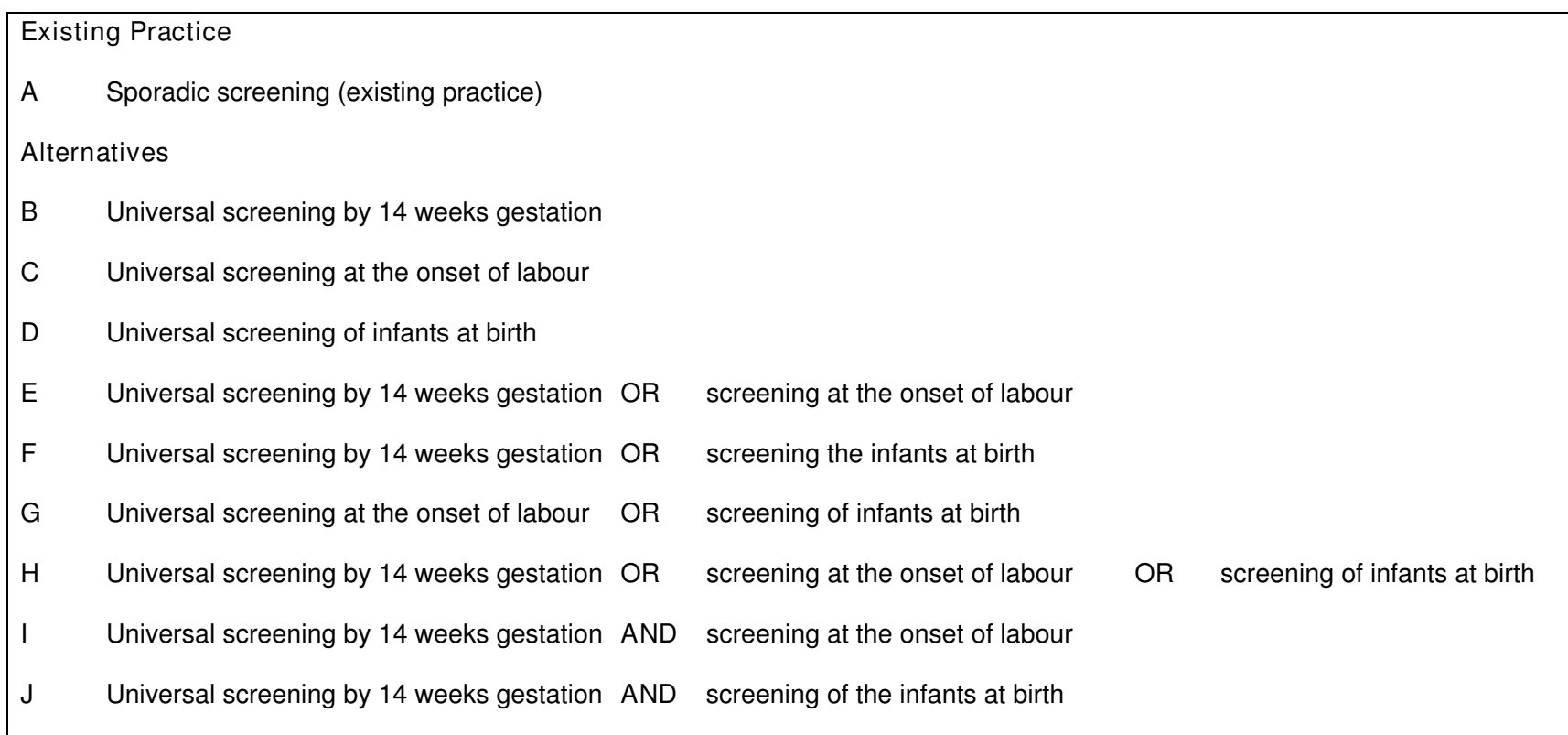

Figure I

Existing Practice and the Nine Alternate Models of Perinatal HIV Screening.

care giving that would have been incurred were deducted from the total costs of screening and treatment to derive the net cost of the strategy.

\section{Incremental Benefits}

Incremental benefits were measured in life years gained (LYG). These included the LYG from avoided HIV infection in infants, and the LYG from earlier detection and treatment of HIV positive mothers and HIV positive infants. In the repeat screening strategies (i.e. E, F, G, H, I \& J) the conservative assumption was made that if a woman refused a first test offer, she would refuse all subsequent test offers. Using the prevalence of HIV and the sensitivity and specificity of the screening test as determined from published literature, the number of true positives and false positives were estimated. It was assumed that not all women diagnosed with HIV would accept antiretroviral therapy (ART) for themselves but would comply with the recommendations for infant prophylaxis, not breastfeeding their infant, and treatment if their infant is HIV+. The ART and prophylaxis protocols for both mothers and infants corresponds to the recommendations from U.S. Preventive Services Taskforce [7]. Rates of perinatal HIV transmission determined from the literature were applied to the number of true positives identified to determine the number of cases of HIV avoided. According to current research, some HIV positive infants would be 'fast' progressors while others would be 'normal' progressors [22-24]. The net LYG would be the number of
LYG from an avoided case of HIV in an infant adjusted for their expected rate of disease progression had they contracted HIV, the LYG from the earlier diagnosis of a HIV positive mother and, the earlier diagnosis of an infant who still contracts HIV despite screening and prophylaxis also adjusted by their expected rate of disease progression.

\section{Uncertainty and sensitivity analyses}

For all variables, the base case, low and high values and the source are presented in Tables 1, 2, 3, 4. The variables for which the model results were most sensitive were identified through a series of one-way sensitivity analyses and this information was summarized in a tornado diagram. These variables were rigorously tested using a threshold and two way sensitivity analysis. To further test the robustness of results to uncertainty within the model, a microsimulation was performed $(\mathrm{n}=10,000$ microsimulations). The intention of a microsimulation is to demonstrate variability in a population and therefore test first order uncertainty in the model. It involves running one patient at a time through the model with the events based on the underlying probabilities in the model. The costs, effects and net monetary benefits are calculated for each run through the model for each strategy.

\section{Results}

With model variables set to baseline values, all strategies generate health benefits and reduce costs when compared 
Table I: Cost Variables (Labour, Counseling \& Testing, Training and Health Promotion) used in model with 'baseline', 'low' and 'high' values, and sources

\begin{tabular}{|c|c|c|}
\hline Variable & Baseline (Low, High) & Source \\
\hline Monthly laboratory technician salary & $\$ 2974(\$ 2230, \$ 3717)$ & [33] \\
\hline Monthly nurses salary & $\$ 4811(\$ 3608, \$ 6013)$ & [33-35] \\
\hline Hourly nurses salary & $\$ 27.75(\$ 20.81, \$ 34.69)$ & {$[33-35]$} \\
\hline Monthly physicians salary & $\$ 16,141(\$ 12,105, \$ 20,176)$ & {$[18,36]$} \\
\hline Hourly physician salary & $\$ 74.50(\$ 55.87, \$ 93.12)$ & {$[18,36]$} \\
\hline Benefits Loading & $30 \%(25 \%, 35 \%)$ & {$[33,36]$} \\
\hline False Positive Rate Elisa Testing & $0.005(0.00 I, 0.2)$ & {$[37,38]$} \\
\hline Sensitivity Elisa Testing & $0.98(0.96,1.0)$ & {$[37,38]$} \\
\hline False Positive Rate Rapid Testing (Oraquick Advance) & $0.002(0.001,0.2)$ & [39] \\
\hline Sensitivity Rapid Testing (Oraquick Advance - Oral Fluid) & $0.993(0.97,1.0)$ & [39] \\
\hline Elisa cost per test & $\$ 4.80(\$ 3.60, \$ 6.00)$ & {$[40]$} \\
\hline Western Blot cost per test & $\$ 48.50(\$ 36.38, \$ 60.63)$ & {$[40]$} \\
\hline Rapid Test cost per test (Oraquick Advance) & $\$ 12.00(\$ 9.00, \$ 15.00)$ & {$[39,40]$} \\
\hline HIV PCR cost per test & $\$ 205.00(\$ 153.75, \$ 256.25)$ & {$[40]$} \\
\hline Monthly laboratory staff allocation - Elisa Test & $0.17(0,0.34)$ & {$[18]$} \\
\hline Monthly laboratory staff allocation - Western Blot & $0.17(0,0.34)$ & {$[18]$} \\
\hline Monthly laboratory staff allocation - HIV PCR & $0.17(0,0.34)$ & [18] \\
\hline Monthly nurse allocation - antenatal care - Elisa test & $0(0,0.5)$ & {$[17,18]$} \\
\hline Monthly nurse allocation - labour and delivery - rapid test & $0(0,0.5)$ & {$[17,18,39]$} \\
\hline Monthly nurse allocation - Nursery - rapid test & $0(0,0.5)$ & {$[17,18,39]$} \\
\hline Pre Test Counseling time - antenatal care (hours) & $0.125(0.094,0.156)$ & {$[17,|8,4|]$} \\
\hline Post Test Counseling time - antenatal care (hours) & $0.17(0.128,0.213)$ & {$[17,|8,4|]$} \\
\hline Pre Test Counseling time - labour or post birth (hours) & $0.17(0.128,0.213)$ & {$[|7| 8,,4 \mid]$} \\
\hline Post Test Counseling time - labour or post birth (hours) & $0.17(0.128,0.213)$ & {$[17,|8,4|]$} \\
\hline Results Release - HIV- time & $0.08(0.00,0.10)$ & {$[17,18]$} \\
\hline Results Release $-\mathrm{HIV}+$ time & $0.5(0.25,0.75)$ & {$[17,18]$} \\
\hline \# of nurses to be trained - Elisa Test (obstetrics clinic) & $32(24,40)$ & {$[17,34]$} \\
\hline \# of nurses to be trained - Rapid Test (labour and delivery) & $34(25,43)$ & {$[17,34]$} \\
\hline \# of nurses to be trained - Rapid Test (nursery) & $26(19,33)$ & {$[17,34]$} \\
\hline \# of training sessions - Elisa Test & $4(2,6)$ & [18] \\
\hline \# of training sessions - Rapid Test & $4(2,6)$ & {$[18]$} \\
\hline Length of training - Elisa Test (hours) & $4.0(3.0,5.0)$ & {$[18]$} \\
\hline Length of training - Rapid Test (hours) & $4.0(3.0,5.0)$ & {$[18,39]$} \\
\hline Training catering costs & $\$ 7.50(\$ 5.00, \$ 10.00)$ & {$[18,42]$} \\
\hline Investment in audiovisual equipment & $\$ 5000(\$ 3750, \$ 6250)$ & [42] \\
\hline Health Promotion activities set up cost & $\$ 2,500(\$ 1875, \$ 3 \mid 25)$ & [42] \\
\hline Annual cost written media items & $\$ 3,900(\$ 2925, \$ 4875))$ & {$[42]$} \\
\hline Annual cost electronic media items & $\$ 25,700(\$ 19,275, \$ 32,125)$ & {$[42]$} \\
\hline
\end{tabular}

to Strategy A which is existing practice. The best alternative is Strategy J, Universal screening by 14 weeks gestation AND screening of the infant at birth. This will save $\$ 737.30$ and generate 0.2037 life years per pregnant women, per annum. Generalizing to the population of the U.S. Virgin islands of 1522 unscreened pregnant women, the implementation of Strategy J would save $\$ 1,122,779$ and generate 310 life years. As compared to existing practice, the strategy would save $\$ 2,209,564$, generate 310 life years, identify an additional 48.14 cases of HIV in mothers and avoid 7.94 cases of HIV in infants. All remaining strategies were dominated by $\mathrm{J}$, that is, they were more costly and less effective. A summary of the results including the cost, effect, incremental cost and incremental effect for each strategy is presented in Table 5. The cost and effect results for each strategy are presented in Figure 2.

The finding that Strategy J was optimal is robust to uncertainty in most model parameters. The best decision changed to strategy $\mathrm{H}$ when the life expectancy of a HIV positive mother with normal diagnosis (i.e. not diagnosed via the screening strategy) was less than 15.9 years or the rate of HIV transmission from mother to infants without treatment was greater than $19.5 \%$. The results of the microsimulation suggest all strategies were dominated by Strategy J, with Strategy J saving \$1079.38 (SD \$17,735) and gain 0.2377 (SD 2.32) life years per antenatal member per annum and save \$1.6 million and gain 362 life years when the entire unscreened antenatal population is considered. 
Table 2: Cost Variables (HIV Treatment - Mother) used in model with 'baseline', 'low' and 'high' values, and sources

\begin{tabular}{|c|c|c|}
\hline Variable & Baseline (Low, High) & Source \\
\hline Antiretroviral medications - pre delivery per month & $\$ 600(\$ 450, \$ 750)$ & {$[40]$} \\
\hline \# of months of medications pre delivery & $6(3,9)$ & {$[2,18]$} \\
\hline Antiretroviral Medications - during delivery & $\$ 400(\$ 300, \$ 500)$ & {$[40]$} \\
\hline Antiretroviral Medications - post delivery per month & $\$ 650(\$ 487.50, \$ 812.50)$ & {$[40]$} \\
\hline Length Physician consults - pre delivery & $0.50(0.37,0.63)$ & {$[18]$} \\
\hline \# Physician consults - pre delivery (per month) & $\mathrm{I}(0.5,1.5)$ & {$[17,18]$} \\
\hline Length of pre delivery period (months) & $6(3,9)$ & {$[2,18]$} \\
\hline Length Physician consults - post delivery & $0.50(0.37,0.63)$ & {$[18]$} \\
\hline \# of Physician consults - post delivery (per month) & 2.00 & {$[18]$} \\
\hline CD4+ cell count - \# per month pre delivery & $0.33(0,250.5)$ & {$[17,18]$} \\
\hline CD4+ cell count $-\#$ during delivery & $\mathrm{I}(0, \mathrm{I})$ & {$[17,18]$} \\
\hline CD4+ cell count - \# per month post delivery & $0.33(0.25,0.5)$ & {$[18]$} \\
\hline Viral load - \# per month pre delivery & $0.33(0.25,0.5)$ & {$[17,18]$} \\
\hline Viral load - \# during delivery & $\mathrm{I}(0, \mathrm{I})$ & {$[17,18]$} \\
\hline Viral load - \# per month post delivery & $0.33(0.25,0.5)$ & {$[18]$} \\
\hline FBC \# per month pre delivery & $0.33(0.25,0.5)$ & {$[17,18]$} \\
\hline FBC \# during delivery & $\mathrm{I}(0, \mathrm{I})$ & {$[17,18]$} \\
\hline FBC \# per month post delivery & $0.33(0.25,0.5)$ & {$[18]$} \\
\hline Hepatitis A, B, C \# per month & $0.083(0,0.17)$ & [18] \\
\hline CD4+ cell count unit cost & $\$ 50(\$ 37.50, \$ 62.50)$ & {$[40]$} \\
\hline Viral Load unit cost & $\$ 205(\$ 153.75, \$ 256.25)$ & {$[40]$} \\
\hline Full Blood Count unit cost & $\$ 10(\$ 7.50, \$ 12.50)$ & {$[40]$} \\
\hline Hepatitis A, B, C unit cost & $\$ 50(\$ 37.50, \$ 62.50)$ & {$[40]$} \\
\hline Pregnancy termination unit cost & $\$ 500(\$ 200, \$ 700)$ & {$[17,43]$} \\
\hline
\end{tabular}

Table 3: Cost Variables (HIV Treatment - Child) used in model with 'baseline', 'low' and 'high' values, and sources

\begin{tabular}{|c|c|c|}
\hline Variable & Baseline (Low, High) & Source \\
\hline Prophylactic antiretroviral medications per week & $\$ 150(\$ 1 \mid 2.50, \$ 187.50)$ & {$[40]$} \\
\hline Duration prophylactic medications (weeks) & $6(4.5,7.5)$ & {$[2,18,44]$} \\
\hline Duration prophylactic medications (weeks) for false positives & $2(0,4)$ & {$[18]$} \\
\hline \# of HIV PCR tests - prophylactic period & $4(2,6)$ & [18] \\
\hline \# of Elisas performed in prophylactic period & $2(0,4)$ & {$[18]$} \\
\hline \# of physician consults during prophylactic period & $19(14,24)$ & {$[18,44]$} \\
\hline \# of physician consultations in prophylactic period for false positives & $2(0,4)$ & [18] \\
\hline Length of physician consult (hours) & $0.25(0.18,0.31)$ & {$[18,44]$} \\
\hline CD4+ cell count $-\#$ per month HIV+ infant & $0.33(0.25,0.5)$ & {$[18,45]$} \\
\hline Viral load - \# per month HIV+ infant & $0.33(0.25,0.5)$ & {$[18,45]$} \\
\hline Full blood count - \# per month HIV+ infant & $0.33(0.25,0.5)$ & {$[18,45]$} \\
\hline Confirmation HIV PCR test unit cost & $\$ 205(\$ 153.75, \$ 256.25)$ & {$[40]$} \\
\hline CD4+ cell count unit cost & $\$ 50(\$ 37.50, \$ 62.50)$ & {$[40]$} \\
\hline Viral Load unit cost & $\$ 205(\$ 153.75, \$ 256.25)$ & {$[40]$} \\
\hline Full Blood Count unit cost & $\$ 10(\$ 7.50, \$ 12.50)$ & [40] \\
\hline Cost ART for a HIV+ infant per month & $\$ 650(\$ 487.50, \$ 8 \mid 2.50)$ & {$[40]$} \\
\hline Infant formula cost per month & $\$ 81(\$ 60.75, \$ 101.25)$ & [44] \\
\hline \# of months formula fed & $12(9,15)$ & [44] \\
\hline Lifetime health care costs of HIV+ infant - normal progressor & $\$ 408,375$ & {$[30]$} \\
\hline Average cost per year - HIV phase & $\$ 4063(\$ 3047, \$ 5078)$ & {$[18,30]$} \\
\hline Average cost per year - AIDS phase & $\$ 13,836(\$ 10,377, \$ 17,295)$ & {$[18,30]$} \\
\hline Caregiver costs per year (HIV phase) & $\$ 9912(\$ 7434, \$ 12,390)$ & {$[18,3 \mid]$} \\
\hline Caregiver costs per year (AIDS phase) & $\$ 27,604(\$ 20,703, \$ 34,505)$ & {$[|8,3|]$} \\
\hline
\end{tabular}


Table 4: Benefit Variables used in model with 'baseline', 'low' and 'high' values, and sources

\begin{tabular}{|c|c|c|}
\hline Variable & Baseline (Low, High) & Source \\
\hline Percentage of pregnant women unscreened through existing practice & $70 \%(50 \%, 90 \%)$ & {$[17,18]$} \\
\hline Annual population pregnant women & $1522(1142,1903)$ & [20] \\
\hline Percentage pregnant women that accept screening - 14 wks gestation & $95 \%(63 \%, 100 \%)$ & {$[17,46-48]$} \\
\hline Percentage pregnant women that accept screening - onset of labour & $85 \%(67 \%, 100 \%)$ & {$[17,49,50]$} \\
\hline Percentage pregnant women that accept screening - infant at birth & $90 \%(67 \%, 100 \%)$ & {$[17,50]$} \\
\hline Percentage pregnant women that accept ART - 14 wks gestation & $75 \%(50 \%, 95 \%)$ & {$[|8,5|]$} \\
\hline Percentage pregnant women that accept ART - onset of labour & $75 \%(50 \%, 100 \%)$ & [18] \\
\hline Percentage of pregnant women that accept ART - infant after birth & $75 \%(50 \%, 100 \%)$ & [18] \\
\hline Prevalence of undiagnosed HIV in women of childbearing age & $4.9 \%(3.6 \%, 6.1 \%)$ & {$[18,52]$} \\
\hline $\begin{array}{l}\text { Additional percentage of screened women who hadn't seroconverted at time of first test or contracted HIV } \\
\text { since first test }\end{array}$ & $2 \%(0 \%, 6 \%)$ & {$[17,25,50]$} \\
\hline$\%$ of women who seek antenatal care prior by 14 weeks gestation & $63.4 \%(47.6 \%, 79.4 \%)$ & {$[17,20]$} \\
\hline $\begin{array}{l}\% \text { of women who seek antenatal care after } 14 \text { weeks and present to hospital in sufficient time prior to } \\
\text { delivery }\end{array}$ & $25.2 \%(19.5 \%, 32.5 \%)$ & {$[17,20]$} \\
\hline Termination of pregnancy in diagnosed HIV+ mothers & $1 \%(0 \%, 5 \%)$ & {$[17,53]$} \\
\hline TR without treatment - no breastfeeding & $28 \%(16 \%, 33 \%)$ & {$[2-4]$} \\
\hline TR with treatment from 14 wks gestation- no breastfeeding & $2 \%(1 \%, 7.3 \%)$ & {$[4,5,54]$} \\
\hline TR with treatment from onset of labour - no breastfeeding & $10 \%(5 \%, 15 \%)$ & {$[4,14,15]$} \\
\hline TR with treatment within 24 hours birth - no breastfeeding & $13.1 \%(8.9 \%, 17.3 \%)$ & {$[15,16]$} \\
\hline Life Expectancy HIV- infant & $77.74(58,97)$ & {$[20]$} \\
\hline Time to Diagnosis of HIV+ infant without screening (months) & $5.2(3.9 .13 .0)$ & {$[55,56]$} \\
\hline $\mathrm{HIV}+$ infant $-\% \mathrm{FP}$ & $25 \%(5 \%, 40 \%)$ & {$[22-24]$} \\
\hline HIV + infant - Time in HIV phase NP (screened) (yrs) & $8.5(5.7,13.5)$ & [57] \\
\hline HIV+ infant - Time in HIV phase NP (unscreened) (yrs) & $6.2(4.7,8.5)$ & [57] \\
\hline HIV+ infant - Time in HIV phase FP (screened) (yrs) & $0.75(0.25,1.25)$ & {$[18,57]$} \\
\hline $\mathrm{HIV}+$ infant - Time in HIV phase FP (unscreened) (yrs) & $0.5(0.0,1.0)$ & {$[18,57]$} \\
\hline HIV+ infant - Time in AIDS phase NP (screened) (yrs) & $4.6(1.7,10.3)$ & {$[18,57]$} \\
\hline HIV+ infant - Time in AIDS phase NP (unscreened) (yrs) & $3.9(1.5,9.7)$ & {$[57]$} \\
\hline HIV+ infant - Time in AIDS phase FP (screened) (yrs) & $0.75(0.25,1.25)$ & [22-24] \\
\hline HIV+ infant - Time in AIDS phase FP (unscreened) (yrs) & $0.5(0.0,1.0)$ & {$[18,22-24]$} \\
\hline Life expectancy HIV+ mother from diagnosis (normal diagnosis path) (years) & $12.0(9.8,18.2)$ & [58] \\
\hline Life expectancy HIV+ mother from diagnosis (early diagnosis due to screening) (years) & $12.70(9.9,15.0)$ & [58] \\
\hline Time to diagnosis of $\mathrm{HIV}+$ mother without screening (months) & $20.4(15.0,25.5)$ & [58] \\
\hline
\end{tabular}

$\mathrm{TR}=$ Transmission Rate

$\mathrm{FP}=$ Fast Progressor

$\mathrm{NP}=$ Normal Progressor

\section{Discussion}

The results indicate all strategies are cost saving and generate health benefits, even strategies that involve repeat screening. This suggests that a decision not to implement universal screening in a setting where prevalence is high and effective therapies can be delivered is unethical. Excess costs will be incurred and life years lost at the same time.

The strategy with the greatest saving and the greatest LYG is Strategy J, universal screening by 14 weeks gestation AND screening of the infant at birth. This will inform the mother of her HIV status if she was not screened by 14 weeks and update the mother if she was screened earlier as some women may have contracted the virus during their pregnancy and some may have not seroconverted at the time of their initial screening. Strategy J was robust to most changes within the model, including a 5\% discount rate for future costs and benefits, but not all. When 'life expectancy of a HIV+ mother with normal diagnosis' took a value of 15.9 years or greater, Strategy J loses its dominance to Strategy $\mathrm{H}$.

The conclusion also changes when alternate values for the rate of transmission with no treatment are applied. For lower values, Strategy $\mathrm{H}$ is the optimal strategy. For higher values, Strategy J is the optimal strategy. Previous studies have also found that their results have been sensitive to the efficacy of treatment but the likelihood that the transmission rate is as low as $19.5 \%$ is minimal $[12,25]$. While transmission rates have been reported as low as $13 \%$, the majority of the studies report transmission rates greater than $25 \%[26]$.

In addition to providing clear policy advice, this study is novel due to the comprehensive range of screening options evaluated. The authors of most studies only evaluate screening women once, at one point in time 
Table 5: Average and Incremental Cost and Effect Outcomes per Pregnant Woman per Annum

\begin{tabular}{|c|c|c|c|c|c|c|}
\hline & Strategy & Cost (\$) & Effect (LYG) & Incremental Cost (\$) & Incremental Effect (LYG) & ICER \\
\hline J & $\begin{array}{l}\text { Universal screening by } 14 \text { weeks gestation } \\
\text { and screening of the infant at birth }\end{array}$ & -737.70 & 0.2037 & & & \\
\hline $\mathrm{H}$ & $\begin{array}{l}\text { Universal screening by } 14 \text { weeks gestation } \\
\text { or screening at the onset of labour or } \\
\text { screening of the infant at birth }\end{array}$ & -730.55 & 0.2013 & 7.15 & -0.0023 & Dominated \\
\hline $\mathrm{F}$ & $\begin{array}{l}\text { Universal screening by } 14 \text { weeks gestation } \\
\text { or screening of the infant at birth }\end{array}$ & -718.82 & 0.2001 & 18.88 & -0.0036 & Dominated \\
\hline 1 & $\begin{array}{l}\text { Universal screening by } 14 \text { weeks gestation } \\
\text { and screening at the onset of labour }\end{array}$ & -646.90 & 0.1627 & 90.81 & -0.0409 & Dominated \\
\hline$E$ & $\begin{array}{l}\text { Universal screening by } 14 \text { weeks gestation } \\
\text { or screening at the onset of labour }\end{array}$ & -639.95 & 0.1636 & 97.76 & -0.0400 & Dominated \\
\hline B & Universal screening by 14 weeks gestation & -600.54 & 0.1485 & 137.16 & -0.0552 & Dominated \\
\hline G & $\begin{array}{l}\text { Universal screening at the onset of labour } \\
\text { or screening the infant at birth }\end{array}$ & -298.17 & 0.1443 & 439.54 & -0.0594 & Dominated \\
\hline C & Universal screening at the onset of labour & -89.46 & 0.0389 & 648.24 & -0.1648 & Dominated \\
\hline $\mathrm{D}$ & Universal screening of the infant at birth & -75.02 & 0.1409 & 662.69 & -0.0628 & Dominated \\
\hline A & Sporadic screening & 714.05 & 0.0000 & $145 \mid .75$ & -0.2037 & Dominated \\
\hline
\end{tabular}

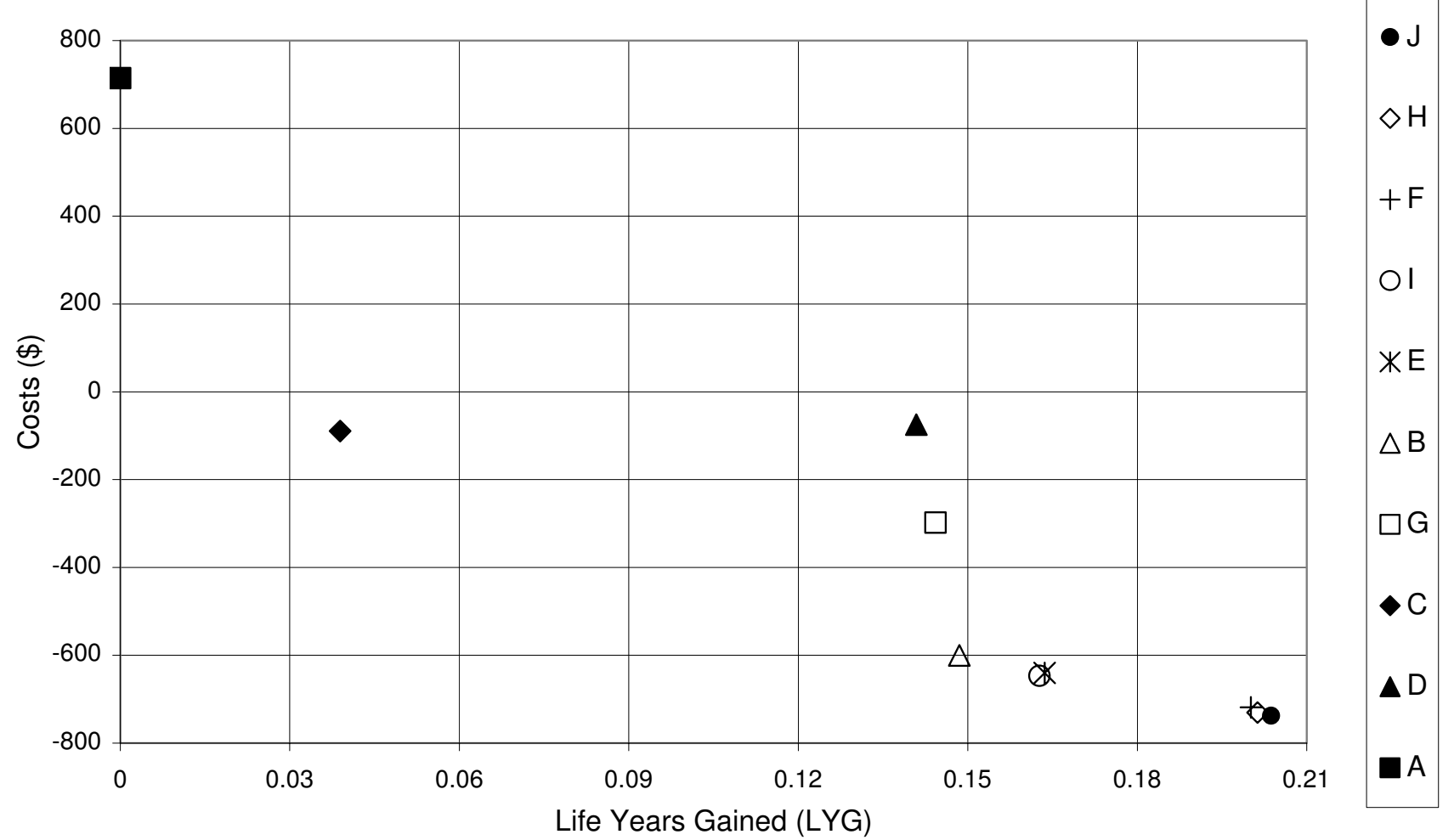

Figure 2

Cost-Effectiveness Plane - Alternate Strategies for Perinatal HIV Screening - US Virgin Islands. 
[8,12,27-29]. The authors of only three studies have compared screening women at more than one point in time [22-24] and none have compared the 'AND' strategies (i.e. strategies I and J) included in this evaluation. The conclusion that repeat screening is cost-effective is therefore novel. The model structure also allows the impact of different rates of disease progression in the infant [22-24], the additional benefits to the mother and infant from early diagnosis, the cost of caring for a child with HIV and AIDS [30,31], the medical costs of a child with HIV and AIDS and the impact of rapid testing [18].

There are several limitations to this research that warrant further investigation. There is little research into the acceptance of a blood specimen as opposed to a saliva specimen for rapid testing and this may affect compliance to testing. Little is known about whether the acceptance of screening may differ between different races, ethnicities and socioeconomic groups. There is also little evidence of the acceptance of HIV treatment recommendations by a mother including the acceptance of treatment for her HIV+ infant and avoiding breastfeeding her HIV+ or HIVinfant. There is the potential that further testing of the mother and/or infant may be required to assess compliance which is not addressed in this study. In addition, the literature indicates that the earlier a woman is diagnosed and ART commenced, the greater the potential to avert virus transmission to the infant. In this study, if a woman does not attend prenatal care by 14 weeks gestation, the next time she would be offered screening is at the onset of labor. There would be a greater potential to avert virus transmission for those who do not attend prenatal care by 14 weeks if they were offered screening earlier than at the onset of labor. These potential additional benefits are not addressed in this study. There is limited data for any population on the incidence of women who seroconvert after the time of their initial test or the incidence of women who contract HIV after their initial screen. This information would be of importance in reinforcing the benefits of offering screening at during more than just the prenatal visit before 14 weeks gestation. Our understanding of the life expectancy of a HIV positive infant, the lifetime health care costs of a HIV positive infant and the treatment regimes for children are constantly changing. Such changes often mean that the previously published literature does not truly reflect the effectiveness of current practice. While we believe that our high and low values for these variables are reasonable and our conclusions are robust to these changes, the continuing improvements in clinical practice should be monitored to ensure that the values for these variables are as reflective as possible of the true cost and effectiveness of current treatment. While the results of the microsimulation demonstrate possible variation in population characteristics, the value of a variable for each simulation is chosen randomly on all levels. Had probability distributions been fitted to model parameters then second order (parameter) uncertainty could have been characterized and cost-effectiveness acceptability curves fitted. This framework also allows the value of reducing uncertainty in model parameters to be estimated, thus providing a valuation of further data collection in the future.

This study highlights that the decision of the U.S. Virgin Islands to adopt standard U.S. policy for perinatal HIV screening is inefficient. Women need to be offered screening more than once and at different points in time. A change to this policy, we suggest, would represent an excellent public health investment, saving nearly 310 life years with an ultimate costs saving of over $\$ 1.1$ million when the entire antenatal population is considered. The study has not only addressed the unique characteristics of the U.S. Virgin Islands but has addressed the cost-effectiveness of antenatal HIV screening for a lower high income country, a country with relatively high HIV prevalence yet relatively substantial resources available to be dedicated to health care. To date, other studies have addressed either high income countries $[8,9,25,29,32]$, or low or lower middle income countries $[10,11]$ but their recommendations are generally not applicable to upper middle income or lower high income countries. These countries may not have the resources to implement strategies recommended for upper high income countries as the range of countries classified as high income is very broad, yet can do more than those recommendations for low income or lower middle income country. Puerto Rico is one country that these results might be generalized to. It is a U.S. Territory that adopts much of its healthcare policy from the mainland U.S. Like the U.S. Virgin Islands, it is a lower upper middle income country with resources available for healthcare. The two countries have similar rates of antenatal care, HIV prevalence greater than that of the mainland U.S. and cases of vertically transmitted HIV are still being diagnosed. Furthermore, both countries are in similar geographical regions with similar population characteristics with Puerto Rico having a higher portion of its population of Hispanic ethnicity. There are several other countries that these results may be generalisable to. While none are as similar in characteristics as Puerto Rico, a country with a similar gross domestic product, mainly upper middle and lower high income countries might benefit from this research owing to the fact that these countries may not have the resources available to implement screening strategies recommended for upper high income countries, yet can do more than the recommended strategies for low income countries. Countries that may fall into this category include other U.S. Territories (Guam and American Samoa), other Caribbean countries (The Bahamas, Aruba, Barbados, St Lucia, St Kitts and Nevis) and even countries within the Americas and 
Europe (Mexico, Hungary and the Czech Republic). In order to generalize, consideration would need to be given to HIV prevalence in women of child bearing age, the rates of prenatal care in the country, acceptance of screening, population and cultural characteristics and the pricing and availability of treatment. Furthermore, the incremental analysis of this study only accounts for the new inputs that are required and does not consider the total costs by including the costs of the existing program. To ensure generalisability between settings, existing program costs, including infrastructure, of the settings would need to be accounted for.

\section{Conclusion}

This study demonstrates the inefficiency of adopting standard perinatal HIV screening policies without addressing a regions population characteristics, HIV prevalence, and the resources available for healthcare. The conclusions provide an opportunity to develop clear, unambiguous and practical policy that will drive costs downward and deliver increased health benefits. This represents an improvement in economic efficiency and a positive step toward treating a serious and prevalent disease. Additionally, this study highlights the benefits of offering screening at different opportunities and of repeat screening. The findings of this study are not only useful to the U.S. Virgin Islands, but raise the question of the generalisability of these results to countries that share similar economic, epidemiological and social characteristics.

\section{Abbreviations}

ART: Antiretroviral Therapy; EIA: Enzyme Linked Immunoassay; HIV: Human Immunodeficiency Virus; ICER: Incremental Cost Effectiveness Ratio; LYG: Life Year Gained; PCR: Polymerase Chain Reaction; TR: Transmission Rate; US: United States of America; U.S. Virgin Islands: United States Virgin Islands.

\section{Competing interests}

The authors declare that they have no competing interests.

\section{Authors' contributions}

BU developed the economic model, reviewed and collected data, performed the analysis and drafted the manuscript. NG contributed to the development of the economic model, performing of the analysis and drafting the manuscript. CU contributed to the development of the economic model and the review and collection of data. All authors read and approved the final manuscript.

\section{Acknowledgements}

Thank you to the health care professionals of the U.S. Virgin Islands for their time, assistance and support of this research with a special mention to Dr Yeon and Dr Ivery.

\section{References}

I. Andiman WA: Transmission of HIV-I from mother to infant. Current Opinion in Pediatrics 2002, I 4(1):78-85.

2. Public Health Service Task Force - Perinatal HIV Guidelines Working Group: Recommendations for the Use of Antiretroviral Drugs in Pregnant HIV-I Infected Women for Maternal Health and to Reduce Perinatal HIV-I Transmission in the United States. In HIVIAIDS Treatment Information Service U.S. Public Health Service; 2005.

3. Connor EM, Mofenson L: Zidovudine for the reduction of perinatal human-immunodeficiency-virus transmission - Pediatric AIDS Clinical Trials Group Protocol 076 - Results and Treatment Recommendations. Pediatr Infect Dis J 1995, 14(6):536-54I.

4. International Perinatal HIV Group: The mode of delivery and risk of vertical transmission of human immunodeficiency virus type I: A meta anaysis of 15 prospective cohort studies. New England Journal of Medicine 1999, 340:977-987.

5. Gonzague Lallemant m], Sophie Le Coeur, Soyeon Kim, Suporn Koetsawang, Marie Comeau Anne, Wiput Phoolcharoen, Max Essex, Kenneth Mclntosh, Vicharn Vithayasai: A Trial of Shortened Zidovudine Regimes to Prevent Mother-to-Child Transmission of human Immunodeficiency Virus Type I. The New England Journal of Medicine 2000, 343(14):982-991.

6. Patrick DMM, Deborah M, Jack Forbes, Dobson Siomon RM, Rekart Michael L, Cook Darrel A, Middleton Peter J, Burdge David R: Routine prenatal screening for HIV in a low-prevalence setting. Canadian Medical Association Journal 1998, I59(8):942-947.

7. U.S. Department of Health and Human Services: Recommendations for the Use of Antiretroviral Drugs in Pregnant HIV-I Infected Women for Maternal Health and Interventions to Reduce Perinatal HIV-I Transmission in the United States. Edited by Force PHST: U.S. Public Health Service; 2005.

8. Ades AE, Sculpher MJ, Gibb DM, Gupta R, Ratcliffe j: Cost effectiveness analysis of antenatal HIV screening in United Kingdom. British Medical Journal 1999, 3 1 9(72 19): 1230-1234.

9. Graves N, Walker D, McDonald A, Kaldor J, Ziegler JB: Would Universal Antenatal Screening for HIV Infection be Cost-Effective in a Setting of Very Low Prevalence? Modelling the Data for Australia. Journal of Infectious Diseases 2004, 190(I): 166-174.

10. Mansergh GMA, Haddix AC, Steketee RW, Nieburg PI, Hu DJ, Simonds RJ, Rogers M: Cost-effectiveness of Short-Course Zidovudine to Prevent Perinatal HIV Type I INfection in a Sub-Saharan African Developing Country Setting. JAMA 1996, 276(2):139-145.

II. Soderlund N, Zwi K, Kinghorn A, Gray G: Prevention of vertical transmission of HIV: analysis of cost effectiveness of options available in South Africa. British Medical Journal 1999, 318(7199): 1650-1656.

12. Zaric GS, Bayoumi AM, Brandeau ML, Owens DK: The Cost Effectiveness of Voluntary Prenatal and Routine Newborn HIV Screening in the United States. Journal of Acquired Immune Deficiency Syndromes 2000, 25(5):403-4I6.

13. Immergluck LCC, William L L, Alan Schwartz, Elstein Arthur S: CostEffectiveness of Universal Compared with Voluntary Screening for Human Immunodeficiency Virus Among Pregnant Women in Chicago. Pediatrics 2000, I05(4):

14. Fiscus SA, Schoenback VJ, Wilfer C: Short Courses of Zidovudine and Perinatal Transmission of HIV. New England Journal of Medicine 1999, 340:1040-104I.

15. Wade N, Birkhead G, Warren B, Charbonneau T, French T, Wang L, Baum J, Tesoriero J, Savicki R: Abbreviated Regimens of Zidovudine Prophylaxis and Perinatal Transmission of the Human Immunodeficiency Virus. The New England Journal of Medicine 1998, 339(20): 1409-1414.

16. Gray G, Chersich MF, Bolton C, Van Niekerk R, Violari A, Stevens W, Mclntyre J: A randomized trial of two postexposure prophylaxis regimens to reduce mother-to-child HIV-I transmission in infants of untreated mothers. AIDS 2005, 19:1289-1297.

17. Ivery D: Personal Communication - Obstetrician/Gynecologist. St Croix, U.S. Virgin Islands; 2002.

18. Yeon P: Personal Communication - Infectious Disease Physician. St Croix, U.S. Virgin Islands; 2002.

19. Data and Statistics - Country Groups [http://www.world bank.org/data/countryclass/classgroups.htm] 
20. Martin JA, Hamilton BE, Sutton PD, Ventura SJ, Manacker F, Munson ML: National Vital Statistics Report. Atlanta: Centers for Disease Control; 2003.

21. Drummond MF, Jefferson TO: Guidelines for authors and peer reviewers of economic submissions to the BMJ. British Medical Journal I996, 313(7052):275-283.

22. Abrams E, Weiner J, Carter R, Kuhn L, Palumbo P, Nesheim S: Maternal Health Factors and Early Pediatric Antiretroviral Therapy Influence the Rate of Perinatal HIV-I Disease Progression in Children. AIDS 2003, I 7:867-877.

23. European Collaborative Study: Fluctuations in Symptoms in Human Immunodeficiency Virus-Infected Children: The First I0 Years of Life. Pediatrics 200I, I08(I): I I6-I 22.

24. Thorne C, Newell M-L, Botet FA, Bohlin A, Ferrazin A, Giaquinto C, Gomez I, Mok JYQ, Mur A, Peltier A: Older Children and Adolescents Surviving with Vertically Acquired HIV Infection. J Acquir Immune Defic Syndr 2000, 29(4):396-40I

25. Sansom S, Jamieson DJ, Farnham PG, Bulterys M, Fowler MG: Human Immunodeficiency Virus Retesting During Pregnancy: Costs and Effectiveness in Preventing Perinatal Transmission. Obstetrics and Gynecology 2003, I 02(4):782-790.

26. Working Group on Mother to Child Transmission of HIV: Rates of mother to child transmission of HIV-I in Africa, American and Europe: Results from 13 perinatal studies. Journal of Acquired Immune Deficiency Syndromes 1995, 8:506-5I0.

27. Grobman WA, Garcia PM: The cost-effectiveness of voluntary intrapartum rapid human immunodeficiency virus testing for women without adequate prenatal care. American Journal of Obstetrics and Gynecology 1999, I8I(5 Pt I): 1062-107I.

28. Mrus JM, Tsevat J: Cost-Effectiveness of Interventions to Reduce Vertical HIV Transmission from Pregnant Women Who Have Not Received Prenatal Care. Medical Decision Mak ing 2004, Jan-Feb:30-39.

29. Postma MJB EJ, Mandalia S, Sherr L, Walters MDS, Houweling H, Jager JC: Universal HIV screening of pregnant women in England: cost effectiveness analysis. British Medical Journal I999, 3 I8(7 | 99): |656-I660.

30. Havens PL, Cuene BE, Holtgrave DR: Lifetime cost of care for children with human immunodeficiency virus infection. The Pediatric Infectious Disease Journal 1997, I6(6):607-610.

31. Wilson L, Moskowitz J, Acree M, Heyman M, Harmatz P, Ferrando S, Folkman S: The Economic Burden of Home Care for Children with HIV and Other Chronic IIInesses. American Journal of Public Health 2005, 95(8): | 445- | 452.

32. Myers ER, Thompson JW, Simpson K: Cost-Effectiveness of Mandatory Compared with Voluntary Screening for Human Immunodeficiency Virus in Pregnancy. Obstetrics and Gynecology 1998, $91(2): 174-181$.

33. Bureau of Labor Statistics [http://www.bls.gov/]

34. Lewis OK: Personal Communication - Nurse. St Croix, U.S Virgin Islands; 2002.

35. Collective Bargaining Agreement Nursing: Nursing Collective Bargaining Agreement Virgin Islands. U.S. Virgin Islands; 2004

36. On-demand HR data and software [http://salary.com]

37. Centers for Disease Control: Update: serologic testing for antibody to human immunodeficiency virus. Morbidity and Mortality Weekly Report 1988, 36:833-840.

38. Owens DK, Nease RFJ, Harris RA: Cost-effectiveness of HIV screening in acute care settings. Archives of Internal Medicine 1996, I 56:394-404.

39. Orasure Technologies Inc: OraQuick Advance Rapid HIV-I/2 Antibody Test. Bethelehem, PA: Orasure Technologies Inc; 2005.

40. St Croix HIV and STD Clinic: HIV Testing Bill from St Croix Laboratories. In Accounting and Billing Records St Croix: U.S. Virgin Islands Department of Health; 2004.

41. Centre for Disease Control and Prevention: Morbidity and Mortality Weekly Report - Revised Guidelines for HIV Conseling, Testing and Referral \& Revised Recommendations for HIV Screening in Pregnant Women. Atlanta: U.S. Department of Health and Human Services; 200I.

42. Virgin Islands Community AIDS Resource and Education Inc: Personal Communication - Non-profit Organization. St Croix: VICARE; 2004.

43. The Cost of Abortions [http://www.aafp.org]

44. Ricketts A: Personal Communication. St Croix 2004
45. Working Group on Antiretroviral Therapy and Medical Management of HIV-Infected Children: Guidelines for the Use of Antiretroviral Agents in Pediatric HIV Infection. UMDNJ, HRSA, NIH; 2005.

46. Aynalem G, Mendoza P, Frederick T, Mascola L: Who and Why? HIV-Testing Refusal During Pregnancy: Implication for Pediatric HIV Epidemic Disparity. AIDS and Behavior 2004, 8(I):25-3I

47. Fernandez MI, Wilson TE, Ethier K, Walter E, Gay C, Moore Acceptance of HIV Testing During Prenatal Care. In Public Health Reports Edited by Services USDoHaH; 2000:460-468.

48. Mayaux M, Teglas JP, Mandelbrot L, Berrebi A, Gallais H, Matheron S, Ciraru-Vigneron N, Parnet-Mathieu F, Bongain A, Rouzioux C: Acceptability and impact of zidovudine for prevention of mother-to-child human immunodeficiency virus-I in France. Journal of Pediatrics 1997, I 3 I(6):857-862.

49. Bulterys M, Jamieson DJ, O'Sullivan MJ, Cohen M, Maupin R, Nesheim S, Webber MP, Van Dyke RB, Wiener J, Branson B: Rapid HIV-I Testing During Labor. Journal of American Medical Association 2004 , 292(2):219-223.

50. Rajegowda BK, Das BB, Lala R, Rao S, Mc Neeley DF: Expedited human immunodeficiency virus testing of mothers and newborns with unknown HIV status at time of labor and delivery. J Perinat Med 2000, 28(6):458-463.

5I. Marseille E, Kahn JG, Mmiro F, Guay L, Musoke P, Fowler MG: Cost effectiveness of single-dose nevirapine regimen for mothers and babies to decrease vertical HIV-I transmission in subSaharan Africa. Lancet 1999, 354(9 I 8I):803-809.

52. Office of HIVIAIDS Surveillance: HIVIAIDS Surveillance Quarterly Report. St Thomas, Virgin Islands: Virgin Islands Department of Health; 2002

53. Kirshenbaum SB, Hirky AE, Correale J, Goldstein RB, Johnson MO Rotheram-Borus MJ, Ehrhardt AA: "Throwing the Dice": Pregnancy Decision-Making Among HIV-Positive Women in Four U.S. Cities. Perspectives on Sexual \& Reproductive Health 2004, 36(3): 106-1 I3.

54. Mofenson L, Lambert JS, Steihm R: Risk factors of perinatal transmission of human immunodeficiency virus type $I$ in women treated with zidovudine. New England Journal of Medicine 1999, 34 I:385-393.

55. Galli L, Demartino M, Tovo PA, Gabiano C, Zappa M, Giaquinto C, Tulisso S, Vierucci A, Guerra M, Marschisio P: Onset of Clinical Signs in Children with HIV-I Perinatal Infection. AIDS 1995 , 9(5):455-46।

56. Morris CR, Araba-Owoyele L, Sector S, Maldonado Y: Disease patterns and survival after acquired immunodeficiency syndrome diagnosis in human immunodeficiency virus-infected children. The Pediatric Infectious Disease Journal 1996, I 5(4):32 I-328.

57. Sculpher MJ, Gibb D, Ades AE, Ratcliffe J, Duong T: Modelling the costs of paediatric HIV infection and AIDS: comparison of infected children born to screened and unscreened mothers. AIDS 1998, I 2: I37I-I380.

58. Gibb DM, Ades AE, Ramyani Gupta, Sculpher Mark J: Cost and benefits to the mother of antenatal HIV testing: estimates from simulation modelling. AIDS 1999, I3(I2): I569-I576.

\section{Pre-publication history}

The pre-publication history for this paper can be accessed here:

http://www.biomedcentral.com/1471-2334/8/174/pre pub 